DOI: $10.17516 / 1999-494 X-0299$

УДК 628.112.001(571.51)

\title{
Reconstruction of the Water Supply to the City of Igarka of Krasnoyarsk Region
}

\author{
Gregory V. Krasavin and Anatoly I. Matiushenko* \\ Siberian Federal University \\ Krasnoyarsk, Russian Federation
}

Received 24.11.2020, received in revised form 18.01.2021, accepted 21.03.2021

\begin{abstract}
Some features of use of water supply systems in the conditions of the Far North are stated. the considered water supply system in Igarka prior to the reconstruction. The reasons for the need for reconstruction of existing water intake facilities are presented. The composition of the reconstructed water intake facilities is described. The experience of operation of reconstructed water supply facilities in Igarka is summarized.
\end{abstract}

Keywords: design and calculation of water sources, surface water sources, reconstruction of existing water intake facilities.

Citation: Krasavin G.V., Matiushenko A.I. Reconstruction of the water supply to the city of Igarka of Krasnoyarsk region, J. Sib. Fed. Univ. Eng. \& Technol., 2021, 14(2), 187-197. DOI: 10.17516/1999-494X-0299

\section{Реконструкция водоснабжения г. Игарки Красноярского края}

Г.В. Красавин, А.И. Матюшенко

Сибирский федеральный университет

Российская Федераиия, Красноярск

Аннотация. Изложены некоторые особенности исполнения систем водоснабжения в условиях Крайнего Севера. Рассмотрены системы водоснабжения г. Игарки до реконструкции. Представлены причины необходимости реконструкции существующих водозаборных сооружений. Изложен состав реконструированных сооружений. Обобщен опыт эксплуатации реконструированных сооружений водоснабжения.

Ключевые слова: проектирование и расчет водозаборов, поверхностные источники водоснабжения, реконструкция водозаборных сооружений.

(C) Siberian Federal University. All rights reserved

This work is licensed under a Creative Commons Attribution-Non Commercial 4.0 International License (CC BY-NC 4.0).

* Corresponding author E-mail address: matyshenko@icoud.com 
Цитирование: Красавин, Г. В. Реконструкция водоснабжения г. Игарки Красноярского края / Г.В. Красавин, А. И. Матюшенко // Журн. Сиб. федер. ун-та. Техника и технологии, 2021, 14(2). C. 187-197. DOI: 10.17516/1999-494X-0299

\section{Введение}

Освоение Севера России является важнейшей частью экономической стратегии страны. Основные запасы природных богатств, включая запасы пресной воды, сосредоточены на территории, занимающей почти три четверти Российской Федерации, и отнесены к северной строительноклиматической зоне. Хозяйственно-экономические и природно-климатические условия Севера различны, но общими для них являются: суровый климат, повсеместное сплошное, прерывистое или островное залегание многолетнемерзлых грунтов (криолитозона), продолжительные зимы до 8-9 месяцев, снегозаносы, пурги, малый меженный сток рек при их перемерзании и др. Для освоения северных территорий требуется надежное бесперебойное круглогодичное водоснабжение населенных мест и объектов промышленности. Водоснабжение в криолитозоне - один из главнейших факторов развития экономики, повышения уровня и качества жизни северян, снижения себестоимости продукции любых производств [1-4]. При организации водоснабжения объектов в любом районе криолитозоны учитывается реальная угроза перемерзания систем водоснабжения, в том числе и самих водоисточников [5-8].

Повышение надежности систем водоснабжения в зоне мерзлоты сводится к поддержанию незамерзаемости водоисточника и всех элементов водозаборного узла [9-16]. Наиболее надежны на Севере водозаборы инфильтрационного типа с фильтрующими водоприемниками, менее других подверженными шуголедовому воздействию. Они обладают хорошими рыбозащитными свойствами и обеспечивают требуемое качество воды при ее отборе. Поэтому при выборе типа водозабора для условий Севера всегда анализируют возможности использования инфильтрационных или фильтрующих водоприемников [11]. Малые и средние реки, перемерзающие на отдельных участках или на всем протяжении, являются наиболее вероятным источником (до 85 \%) водоснабжения на Крайнем Севере [17-19].

За период освоения Севера выработаны различные приемы и технические решения водоснабжения из рек, не имеющих зимой достаточного объема поверхностного стока. Одними из них являются инфильтрационные водозаборы на малых реках Крайнего Севера, позволяющие обеспечивать надежный водозабор во всех случаях, когда годовое водопотребление составляет не менее 3-5 тыс. м³/сут. Источниками инфильтрационной воды в зимний период служат талики под руслами и долинами рек [10, 12, 19, 20].

Для повышения надежности работы инфильтрационных водозаборов в зимний период на малых реках Крайнего Севера используют временные (сезонные) водохранилища путем создания ледовых и ледово-грунтовых плотин, появляющихся в период начала ледостава и разрушающихся естественным образом в весенний период ледохода. При этом обводняются подрусловые отложения, предотвращается образование наледей, улучшается тепловой режим водозаборов. При необходимости запас воды может увеличиваться намораживанием льда в начале зимы по всей площади акватории водозаборов слоем до 3-7 м. Так как часто на малых перемерзающих реках лед тает на месте без ледохода, возможно его использование в качестве материала для временных плотин, облегченных подпорных сооружений для накопления меженного стока $[9,18,19]$. 


\section{Реконструкции водозаборных сооружений в г. Игарке}

На средних и крупных реках Крайнего Севера для обеспечения водоснабжения населенных пунктов и городов численностью порядка 4-5 тыс. человек, включая промышленные предприятия, экономически целесообразно использовать открытые водозаборы руслового или берегового типов. При этом необходимо учитывать специфику условий работы таких водозаборов, связанную с перепадами уровней воды в реках Севера, достигающими, к примеру, на Енисее в районе г. Игарки более 20 м, что требует специальных инженерных решений берегоукрпления в районе водозаборов. Но в отличие от инфильтрационных водозаборов водозаборы из открытых источников, как правило, нуждаются в дополнительной очистке и обеззараживании согласно требованиям санитарных правил и норм [21].

Конкретным примером современного инженерного решения водоснабжения северного города Игарки (рис. 1) служит реконструкция водоснабжения из р. Енисей, проведенная специалистами ОАО «Красноярский институт ВОДОКАНАЛПРОЕКТ».

До проведения реконструкции водозаборных сооружений в г. Игарке хозяйственнопитьевое водоснабжение осуществляли из временного открытого водозабора на р. Гравийка производительностью 4000 м³/сут. Вода через фильтрующие оголовки по самотечным водоводам поступала в два береговых шахтных колодца и затем насосной станцией 1-го подъема после обеззараживания гипохлоритом натрия по двум напорным водоводам диаметром 250 мм, длиной 3,5 км поступала в магистральные сети города и насосную станцию 2-го подъема, подкачивающую воду в сети города. С 1969 года система водоснабжения эксплуатировалась без



Рис. 1. Общий вид г. Игарки

Fig. 1. General view of Igarka 
капитального ремонта. Износ системы составлял 80-95 \%, сооружения насосной станции 1-го подъема и напорные стальные водоводы находились в полуаварийном состоянии. Качество воды из водозабора не соответствовало действующим нормам. Кроме того, в отдельные годы p. Гравийка перемерзала полностью, что приводило к остановке забора воды.

Водозаборные сооружения Игарского лесопильно-перевалочного комбината (ЛПК) выполнены по проекту «Ленгипродрев» и построены в 1968 году. Сооружения открытого типа из р. Енисей расположены на протоке Игарской. Вода из реки забиралась фильтрующими оголовками и по двум самотечным водоводам диаметром 426 мм поступала в береговой колодец, совмещенный с насосной станцией 1-го подъема, на площадку Игарского ЛПК и в старую застройку огорода. В настоящее время водозаборные сооружения законсервированы и не эксплуатируются по причине их аварийного состояния.

Важным элементом транспортного сообщения г. Игарки с «большой землей» является авиационное снабжение. Аэропорт расположен на острове Игарском. Остров находится напротив города и разделен протокой Енисея. На острове помимо аэропорта расположена котельная, а также соответствующие производственные и служебные сооружения. Для обеспечения водоснабжения на острове существует водозабор. Хозяйственно-питьевые нужды населения и котельной обеспечиваются из подземного водозабора с помощью двух скважин глубиной 100 м общим дебитом 336 м³/сут. Источником воды служит водоносный пласт, расположенный ниже слоя вечной мерзлоты.

Для снабжения горячей водой бытовых и производственных нужд населения, а также отопления зданий, сооружений и водоводов наземной прокладки в городе созданы временные водозаборные сооружения центральной отопительной котельной (ЦОК). Береговая насосная станция для подачи воды в центральную отопительную котельную для отопления жилого массива была построена на берегу протоки Игарской в 1985 году. Вода этой станцией подается потребителям без очистки и обеззараживания, поэтому качество воды не соответствует действующим нормам.

Анализ представленных выше водозаборных сооружений г. Игарки, выполненных в 6080-е годы прошлого столетия, свидетельствует о крайне неудовлетворительном качестве воды, поставляемой потребителям, а также о предельном износе технических средств и объектов капитального строительства. Для решения назревших проблем требовалась реконструкция водоснабжения в целом и водозаборных сооружений в частности. С этой целью в ОАО «Красноярский институт ВОДОКАНАЛПРОЕКТ» была разработана проектная документация на строительство сооружений водоснабжения «КЕССОН».

Схема водоснабжения по проекту реконструкции представлена следующим образом. С помощью фильтрующих русловых оголовков по самотечно-сифонным линиям вода из протоки Игарской поступает в насосную станцию 1-го подъема и далее на водоочистные сооружения. После очистки и обеззараживания вода насосами 2-го подъема по двум водоводам протяженностью 3,1 км из стальных труб диаметром $273 \times 6$ мм подается на площадку существующего водопроводного узла г. Игарки. Схема водоснабжения приведена на рис. 2.

В состав реконструируемых водозаборных сооружений хозяйственно-питьевого водоснабжения вошли следующие наиболее значимые объекты: русловой водозаборный оголовок; самотечно-сифонный водовод с насосной станцией 1-го подъема (рис. 3), производительно- 


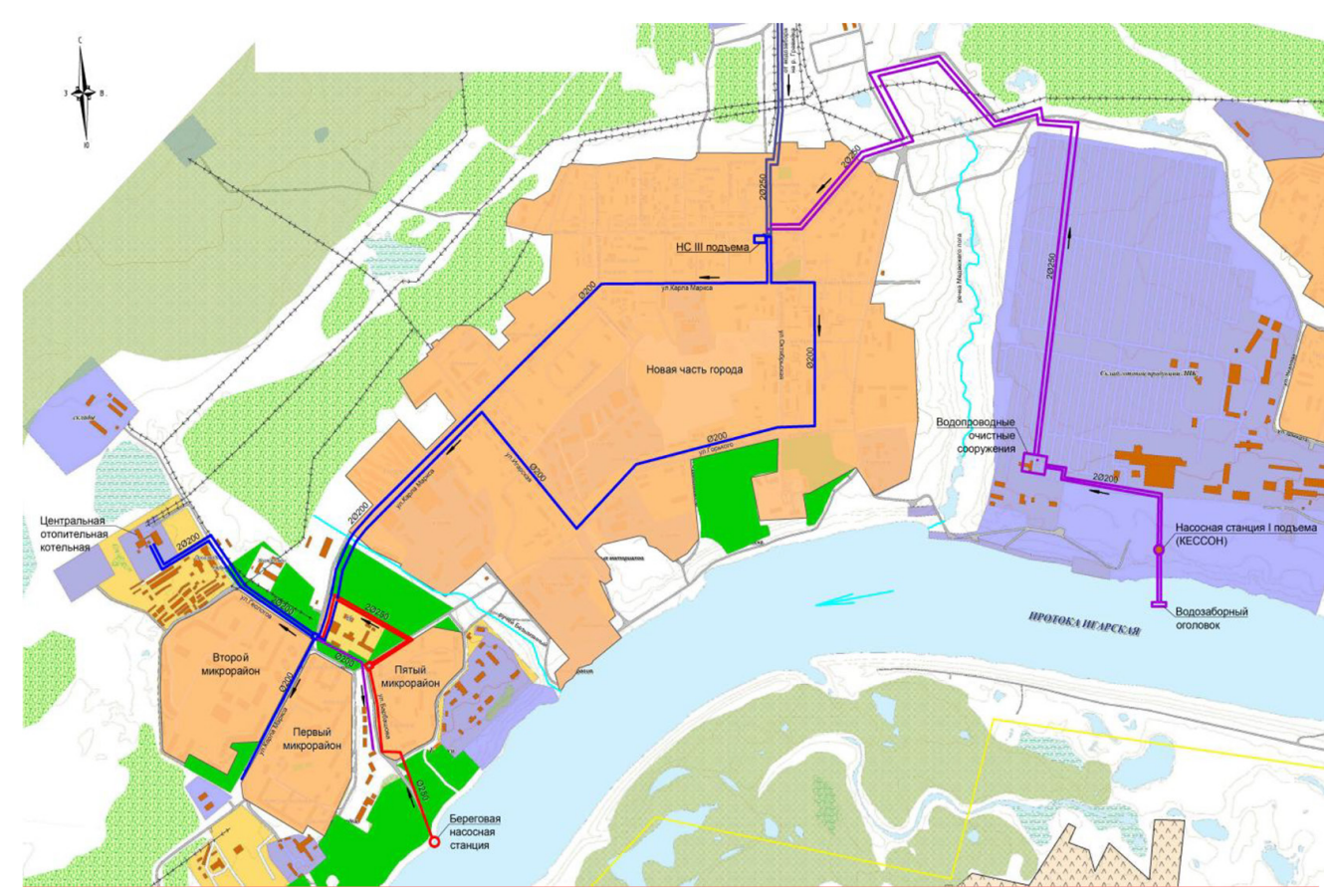

Рис. 2. Схема водоснабжения г. Игарки

Fig. 2. Water supply scheme in Igarka

стью 4200 м³/сут; водовод надземной прокладки в две нитки от насосной станции 1-го подъема до станции очистки воды длиной 0,6 км; сооружения очистки воды для хозяйственно-питьевых целей производительностью $4200 \mathrm{~m}^{3}$ /сут; насосная станция 2-го подъема производительностью

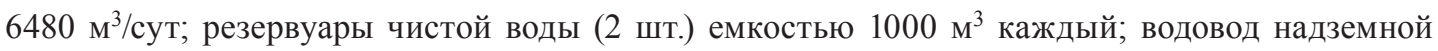
прокладки от насосной станции 2-го подъема до насосной станции подкачки в городе длиной 3,1 км в две нитки.

Проектом реконструкции водозабора предусмотрено устройство нового водоприемного оголовка раструбного типа. Конструкция оголовка принята по типовому проекту. Оголовок смонтирован на железобетонной плите размером $2 \times 2$ м и состоит из двух секций. Каждая секция оборудована съемной фильтрующей рыбозащитной самоочищающейся кассетой размером $1 \times 0,6$ м, совмещенной с сороудерживающей решеткой. Рыбозащита обеспечена малыми входными скоростями воды, которые в 8-10 раз меньше скоростей течения в протоке в межень $(0,3$ м/с). Для защиты оголовка от плывущего льда вокруг него предусмотрена свайная защита. Незначительная мутность речной воды (4-62 г/м $\left.{ }^{3}\right)$ и конструктивная возможность самоочищения препятствуют заиливанию водоприемника.

Самотечно-сифонные водоводы подают воду от руслового водоприемного оголовка к насосной станции 1-го подъема по двум стальным трубам диаметром $325 \times 8$ мм и длиной 105 м. Глубина заложения трубопроводов составляет от 1 до 20 м. Подводная часть водоводов выполнена с усиленной наружной гидроизоляцией и внутренним лакокрасочным покрытием эмалью. Защита наружной гидроизоляции сделана сплошной футеровкой деревянными рейками. Стыковка труб с оголовком осуществлена с помощью полумуфт с резиновым уплотнением. 
Подводная часть водоводов проложена в открытой траншее методом свободного погружения, подземная часть водоводов выполнена методом продавливания от береговой черты до насосной станции 1-го подъема.

При модернизации насосной станции использовано существовавшее сооружение. Насосная станция производительностью 4200 м³/сут сблокирована с двухсекционным водоприемником. Подземная часть насосной станции диаметром 10 м представляет собой железобетонный колодец - кессон глубиной 27,7 м. Колодец разделен вертикальной стенкой на водоприемник и «сухой» машинный зал. Водоприемник разделен перегородкой на две секции, в каждую из которых вводится самотечно-сифонный водовод. В машинном зале установлены основные насосы фирмы «GRUNDFOS» марки NB65-200/190 мощностью 18,5 кВт каждый, два рабочих, один - резервный (рис. 3).

Для осушения водоприемной камеры при ремонтных работах предусмотрен переносной погружной насосный агрегат «ГНОМ» $40 \times 25$ мощностью 4 кВт. Зарядка сифонных водоводов
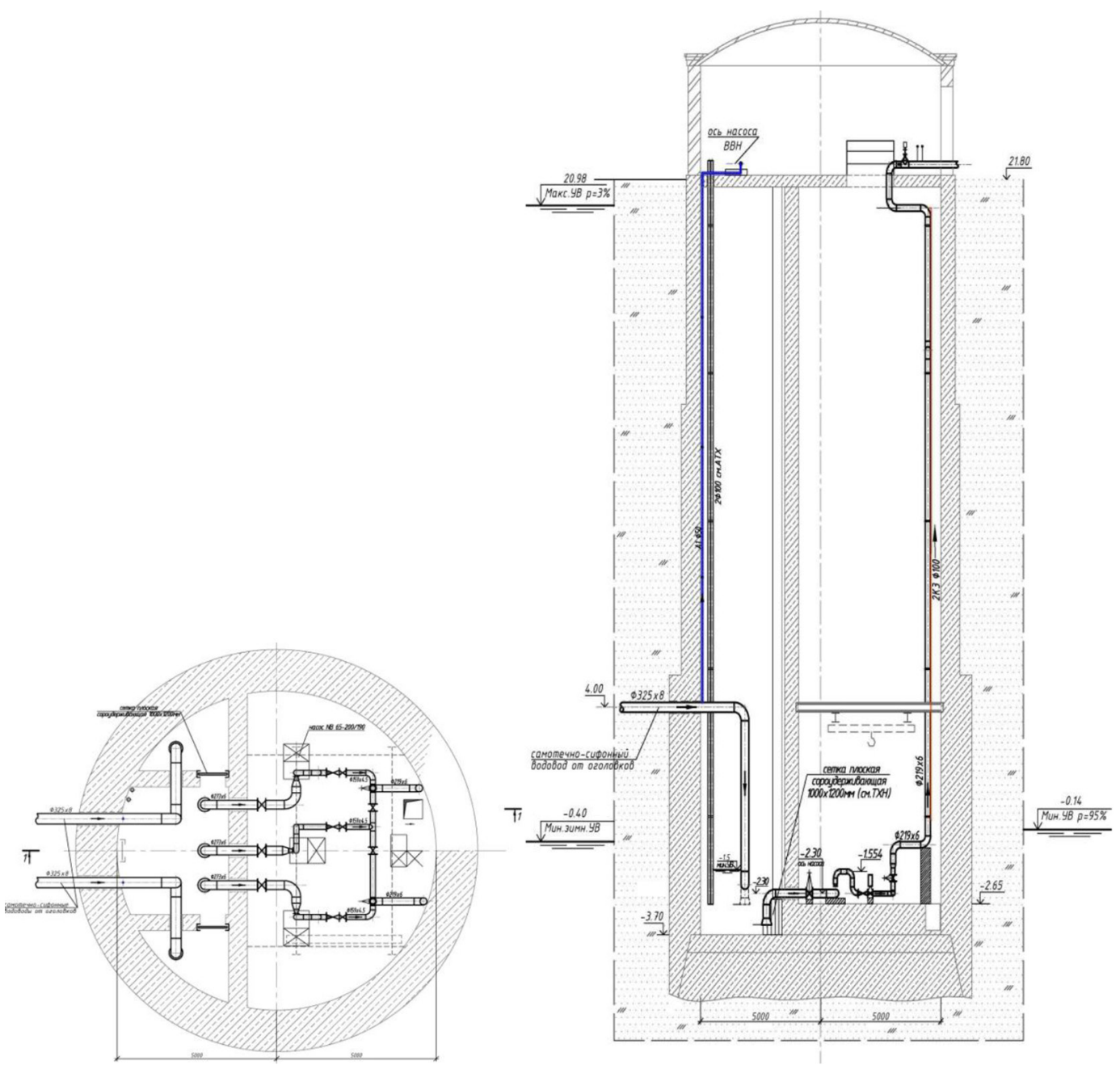

Рис. 3. Насосная станция 1-го подъема

Fig. 3. Pumping station of the first lift 
и поддержание нормального режима их работы выполнены вакуумной установкой с двумя насосами BВН1-1,5, из которых один рабочий, другой резервный. Для откачки дренажных вод предусмотрены два насоса ВК 4/28 мощностью 7 кВт каждый. В надземной части насосной станции расположено электротехническое оборудование, монтажная площадка, установка вентиляции, служебные помещения. Все основные технологические процессы работы насосной станции автоматизированы. Управление и контроль за работой узла осуществляются с диспетчерского пункта на станции очистки воды.

Напорные водоводы от насосной станции 1-го подъема до площадки водопроводных очистных сооружений выполнены двумя стальными трубами диаметром $219 \times 6$ мм с тепловой пенополиуретановой изоляцией с защитной оболочкой из оцинкованной стали с саморегулирующимся греющим электрическим кабелем. Прокладка труб выполнена наземной на лежневых опорах, размещенных на грунтовых призмах. Для опорожнения напорных водоводов предусмотрена установка пожарных гидрантов в незамерзающем исполнении. Отведение воды при опорожнении производится пожарными рукавами в пониженные места.

В период паводка и ледохода вода в районе водозабора поднимается более чем на 22 м. Для предотвращения размыва площадки водозаборных сооружений в период паводковых высоких вод и ледохода выполнено берегоукрепление из сборных железобетонных плит размером $3 \times$ $1,5 \mathrm{м}$.

Очистка исходной воды после водозабора, подъема на насосной станции 1-го подъема производится на комплексе блочно-модульной станции водоподготовки, разработанной ЗАО «Компания ЭКОС» (рис. 4).

Схема очистки малозагрязненных природных поверхностных вод до показателей, соответствующих санитарным нормам, производится на станции очистки воды и предусматривает



Рис. 4. Комплекс блочно-модульной станции водоподготовки

Fig. 4. Complex of block-modular water treatment plant 


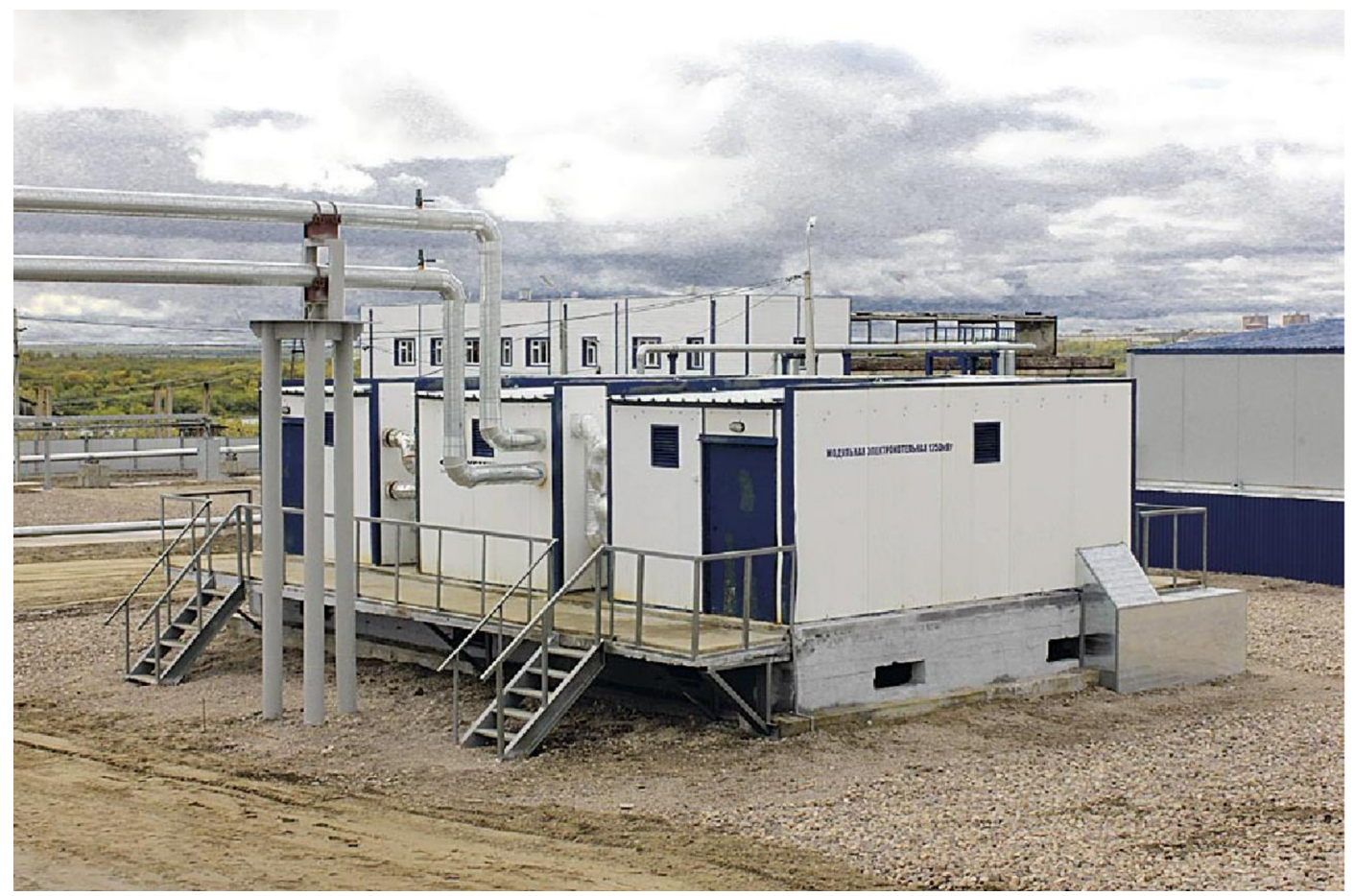

Рис. 5. Станция очистки воды

Fig. 5. Water treatment plant

следующие стадии технологического процесса: фильтрация на сетчатых фильтрах; контактное осветление; фильтрация на фильтрах с загрузкой активированным углем; обеззараживание; нагрев; наполнение в резервуары чистой воды и подача потребителю (рис. 5).

Исходная вода подается под напором на сетчатые фильтры, которые промываются в автоматическом режиме. После предварительной механической очистки вода поступает во входную камеру и на контактные осветлители. Перед этим в воду вводится раствор коагулянта. Промывка контактного осветлителя водовоздушная, подача промывной воды осуществляется из насосов производительностью 85 м $3 / ч$ и напором 20 м. Воздух подает воздуходувка с производительностью 510 м $3 /$ и и напором 10 м. Отвод промывной воды идет в два резервуара грязных промывных вод с последующей откачкой ассенизационной машиной.

Обеззараживание воды производят низкоконцентрированным (0,8 \%-ным) раствором гипохлорита натрия, полученным электролизным способом на установке Clorogen CLGH-500 из пищевой соли. Производительность электролизной по активному хлору 12,6 кг в сутки. Расход соли при этом составляет 44,1 кг/сут. Время контакта активного хлора с водой обеспечено в резервуаре чистой воды и равно не менее 30 мин согласно санитарным правилам и нормам. Принятая доза по активному хлору 2-3 мг/л. Доза остаточного хлора 0,3-0,5 мг/л. Контроль свободного хлора осуществляется датчиком.

Устранение в воде остатков органических веществ, цветности воды и запахов производится на фильтрах с загрузкой активированным углем. Технология фильтрации предусматривает взрыхление и промывку сорбционной загрузки. Взрыхление осуществляют от насосов подачи 
промывной воды, подача воздуха - от воздуходувки. Взрыхление угольных фильтров обеспечивает их промывку и регенерацию. Отвод промывной воды предусматривается в резервуары грязных промывных вод с последующей откачкой ассенизационной машиной. Несоблюдение технологии взрыхления может приводить к выбросу адсорбента и загрязнению воды.

Для исключения замерзания воды в водоводах в часы минимального водоразбора и выполнения требований эксплуатирующей организации г. Игарки в схеме водоснабжения предусмотрен подогрев воды до $20^{\circ} \mathrm{C}$. После сорбционных фильтров очищенная и обеззараженная вода поступает в установку нагрева «Титан», состоящую из двух узлов «Титан-500» и «Титан-750». Нагрев осуществляется индукционным электронагревателем «Эдиссон-250». Для циркуляции теплоносителя установлен циркуляционный насос. Установка нагрева работает в автоматическом режиме. Подогретая вода поступает в резервуар чистой воды и далее насосами 2-го подъема подается потребителям. Контроль качества воды перед ее поступлением в распределительную сеть на водопроводной очистительной станции осуществляется в лаборатории по органолептическим показателям и химическому составу.

\section{Выводы}

В результате проведенной реконструкции сооружений и оборудования системы хозяйственно-питьевого водоснабжения г. Игарки по проектной документации ОАО «Красноярский институт ВОДОКАНАЛПРОЕКТ» с момента сдачи в эксплуатацию в сентябре 2017 года город получил надежное и качественное водоснабжение. Этому способствовало внедрение передовых технологий водоподготовки и подачи воды потребителям. Современный уровень водоснабжения населения и предприятий города обеспечен автоматизацией основных технологических процессов, что позволило вести контроль и управление всех узлов подачи воды с диспетчерского пункта на блочной станции очистки. Большую роль в повышении надежности работы систем водоснабжения играет применение современного гидромеханического, электрического оборудования, КИП и автоматики, систем диспетчеризации и связи.

\section{Список литературы / References}

[1] Матюшенко А.И. Кулагин В.А., Турутин Б. Ф. Экология водопользования в криолитозоне. М.: Маджента, 2013. 376 с. [Matyushenko A.I. Kulagin V. A., Turutin B. F. Ecology of water use in the permafrost zone. Moscow, Magenta, 2013. 376 p. (In Russian)]

[2] Матюшенко А.И., Т Турутин Б.Ф., Лютов А.В. Инженерно-экологические основы систем водоснабжения Сибири и Крайнего Севера. Красноярск: КрасГАСА, 2000. 158 с. [Matyushenko A.I., Turutin B.F., Lyutov A.V. Engineering and ecological foundations of water supply systems in Siberia and the Far North. Krasnoyarsk, KrasGASA, 2000, 158 p. (In Russian)]

[3] Матюшенко А. И., Лютов А. В., Кулагин В. А., Турутин Б. Ф. Теплофизика систем водоснабжения. Красноярск: ИПЦ КГТУ, 2002. 224 с. [Matyushenko A. I., Lyutov A. V., Kulagin V.A., Turutin B.F. Thermal physics of water supply systems. Krasnoyarsk, IPTs KSTU, 2002. 224 p. (In Russian)]

[4] Матюшенко А.И., Турутин Б.Ф., Лютов А.В. Комплексное использование водных ресурсов (Восточно-Сибирские регионы); ред. Б. Ф. Турутин. Красноярск: ИПЦ КГТУ, 2003. 
300 c. [Matyushenko A. I., Turutin B. F., Lyutov A. V. Integrated use of water resources (East Siberian regions); ed. B. F. Turutin. Krasnoyarsk, IPC KSTU, 2003. 300 p. (In Russian)]

[5] Кулагин В. А., Крючков Г.П. Инженерно-экологическая особенность проектирования водозаборных сооружений сибирских регионов. Экология урбанизированных территорий, 2007, 3. 65-68. [Kulagin V.A., Kryuchkov G.P. An engineering and environmental feature of the design of water intake facilities in Siberian regions. Ecology of urbanized areas, 2007, 3, 65-68. (In Russian)]

[6] Матюшенко А.И., Кулагина Т.А., Шайхадинов А.А., Тугужаков Д.Б. Повышение эффективности эксплуатации трубопроводов в условиях Сибири и Крайнего Севера. Журнал СФУ. Техника и технологии, 2015, 8(2), 216-226. [Matyushenko A. I., Kulagina T. A., Shaikhadinov A. A., Tuguzhakov D. B. Improving the efficiency of pipeline operation in Siberia and the Far North. J. Sib. Fed. Univ. Eng. technol., 2015, 8(2), 216-226. (In Russian)]

[7] Кулагин В. А., Кулагина Т. А., Матюшенко А. И., Турутин Б. Ф. Физика атмосферы и гидрофизика. Красноярск: ИПЦ КГТУ, 2006. 498 с. [Kulagin V. A., Kulagina T. A., Matyushenko A. I., Turutin B.F. Physics of the atmosphere and hydrophysics. Krasnoyarsk, IPC KSTU, 2006. 498 p. (In Russian)]

[8] Турутин Б. Ф., Лютов А. В., Матюшенко А. И. Экология и системы водоснабжения в условиях Сибири: Матер. международной конференции по экологии. Иркутск, 1996. [Turutin B.F., Lyutov A. V., Matyushenko A.I. Ecology and water supply systems in Siberia: Mater. international conference on ecology. Irkutsk, 1996. (In Russian)]

[9] Матюшенко А.И., Яковлева М.Г. Повышение интенсивности работы инфильтрационных водозаборов с учетом сложных теплофизических условий сибирских регионов. Вестник ИрГТУ, 2010, 6(46), 162-170. [Matyushenko A. I., Yakovleva M. G. Increasing the work intensity of infiltration water intakes, taking into account the complex thermophysical conditions of the Siberian regions. ISTU Bulletin, 2010, 6(46), 162-170. (In Russian)]

[10] Турутин Б.Ф., Матюшенко А.И. Водозаборные сооружения из подземных источников (теория, расчет и оптимизаџия). Красноярск: КГТУ, 1996. 184 с. [Turutin B.F., Matyushenko A. I. Intake structures from underground sources (theory, calculation and optimization). Krasnoyarsk, KSTU, 1996. 184 p. (In Russian)]

[11] Порядин А.Ф. Устройство и эксплуатация водозаборов. М.: Стройиздат, 1984. 183 с. [Poryadin A.F. Construction and operation of water intakes. Moscow, Stroyizdat, 1984. 183 p. (In Russian)]

[12] Вдовин Ю.И. Водоснабжение на Севере. Л.: Стройиздат, Ленинградское отд. 1987. 166 c. [Vdovin Yu. I. Water supply in the North. L., Stroyizdat, Leningrad dep. 1987. 166 p. (In Russian)]

[13] Вдовин Ю. И. Забор воды из перемерзающих рек. Водоснабжение и санитарная техника, 1989, 4, 20-22. [Vdovin Yu. I. Water intake from freezing rivers. Water supply and sanitary equipment. 1989, 4, 20-22. (In Russian)]

[14] Вдовин Ю. И. Направления совершенствования систем водоснабжения в районах Севера. Современные технологии водоснабжения: Сб. материалов ДВПТИ. Владивосток, 1990, 81-85. [Vdovin Yu.I. Directions for improving water supply systems in the North. Modern water supply technologies: Sat. materials DVPTI. Vladivostok, 1990, 81-85. (In Russian)].

[15] Матюшенко А.И., Турутин Б.Ф., Кулагин В.А. Водоснабжение и водопотребление г. Красноярска. Красноярск: ИПЦ КГТУ, 2006. 329 с. [Matyushenko A.I., Turutin B.F., 
Kulagin V. A. Water supply and water consumption in Krasnoyarsk. Krasnoyarsk, IPTs KSTU, 2006. 329 p. (In Russian)].

[16] Шонина Н. А. Водоснабжение и водоотведение в условиях Крайнего Севера. Санитарная техника, 2012, 5, 32-43. [Shonina N. A. Water supply and sewerage in the Far North. Sanitary engineering. 2012, 5, 32-43. (In Russian)]

[17] Аржакова С. К. Минимальный сток рек криолитозоны России. Санкт-Петербург: Изд. РГГМУ, 2001. 208 c. [Arzhakova S. K. The minimum flow of rivers in the permafrost zone of Russia. St. Petersburg, Publishing house. RGGMU, 2001. 208 p. (In Russian)]

[18] Файко Л.И. Использование льда и ледовых явлений в народном хозяйстве. Красноярск: Изд. Красноярского ГУ, 1986. 158 с. [Faiko L.I. Use of ice and ice phenomena in the national economy. Krasnoyarsk, Ed. Krasnoyarsk State University, 1986. 158 p. (In Russian)]

[19] Вдовин Ю.И., Вишневская Н.С. Водозаборно-очистные сооружения в системах водоснабжения в криолитозоне России. М.: Изд. РУДН, 2007. 236 с. [Vdovin Yu.I., Vishnevskaya N.S. Water intake and treatment facilities in water supply systems in the permafrost zone of Russia. Moscow, Ed. RUDN, 2007. 236 p. (In Russian)]

[20] Пособие по проектированию сетей водоснабжения и канализачии в сложных инженерно-геологических условиях (к СНиП 2.04.02-84 и 2.04.03-85). М.: Союзводоканалпроект, 1990. 56 с. [Manual for the design of water supply and sewerage networks in difficult engineering and geological conditions (to SNiP 2.04.02-84 and 2.04.03-85). M., Soyuzvodokanalproekt, 1990. 56 p. (In Russian)]

[21] Матюшенко А.И., Красавин Г.В. Особенности проектирования водозаборов в условиях Севера. Журнал СФУ. Техника и технологии, 2018, 11(1), 116-122. [Matyushenko А.І., Krasavin G. V. Features of the design of water intakes in the North. J. Sib. Fed. Univ. Eng. technol., 2018, 11(1), 116-122. (In Russian)] 